\title{
Non-linearity in radiocaesium soil to plant transfer: Fact or fiction?
}

\author{
N.A. Beresford and S.M. Wright \\ Centre for Ecology \& Hydrology, Lancaster Environment Centre, Library Avenue, Bailrigg, \\ Lancaster LA1 4AP, UK, e-mail: nab@ceh.ac.uk
}

\begin{abstract}
The basis premise of many radiological assessments is the assumption that the transfer of many radionuclides from soil to herbage and hence animal derived food products is a positive linear relationship for a given set of ecological conditions. However, a number of authors have published results, which they conclude demonstrate non-linear transfer of radiocaesium to plants and animals with transfer being highest when soil concentrations are lowest. Whilst we may expect non-linear transfer of radionuclides under homeostatic control or present in comparatively large chemical quantities, there appears no credible hypothesis to support such an observation for radiocaesium. In this paper we review those articles, which have reported non-linear radiocaesium transfer and also analyse novel data. We argue that saturation of Cs uptake as suggested by some other authors is unlikely. Sampling bias, statistical data distribution and countermeasure application are suggested as potential contributors. However, we have not been able to provide a conclusive reason for such observations. Given the important implications for foodchain modelling further consideration of available data is required to more comprehensively answer this question.
\end{abstract}

\section{INTRODUCTION}

The basis premise of many radiological assessments is the assumption that the transfer of many radionuclides from soil to herbage and hence animal derived food products is a positive linear relationship for a given set of ecological/agricultural conditions (e.g. [1-3]). There are a number of radionuclides, which are either under homeostatic control (e.g. dietary $\mathrm{Ca}^{2+}$ will determine ${ }^{90} \mathrm{Sr}$ transfer to milk etc. [4]) or present in comparatively large chemical quantities [5] for which this is not the case. For radiocaesium, however, whilst the influence of factors such as soil solution $\mathrm{K}^{+}$ concentration, soil pH, clay and organic matter content of soils is now acknowledged [6], the assumption of linearity in transfer has generally been accepted. [7]

During the course of analysing post-Chernobyl data describing ${ }^{137} \mathrm{Cs}$ to milk and potatoes from the former Soviet Union (fSU) the authors observed what appeared to be non-linear transfer from soil to milk and potatoes. Figure 1 presents data for milk and potatoes showing apparent decreases in ${ }^{137} \mathrm{Cs}$ transfer (expressed as the aggregated transfer parameter, Tag, defined as the ratio of the ${ }^{137} \mathrm{Cs}$ activity concentration in milk or potatoes $\left(\mathrm{Bq} \mathrm{kg}^{-1}\right)$ to the ${ }^{137} \mathrm{Cs}$ activity per unit area $\left(\mathrm{Bq} \mathrm{m}{ }^{-2}\right)$ ) with increasing deposition. A review of the available literature showed that other authors had reported similar observations both within the fSU [e.g. 8-10] and Western Europe [e.g. 11-14]. This has obvious implications for foodchain models and potentially countermeasure implementation.

In this paper we present an overview of previously reported observations of decreasing radiocaesium transfer with increasing soil radiocaesium. Possible reasons for these observations, as presented by the original authors, are discussed and an analysis of the data within Figure 1 is presented. 

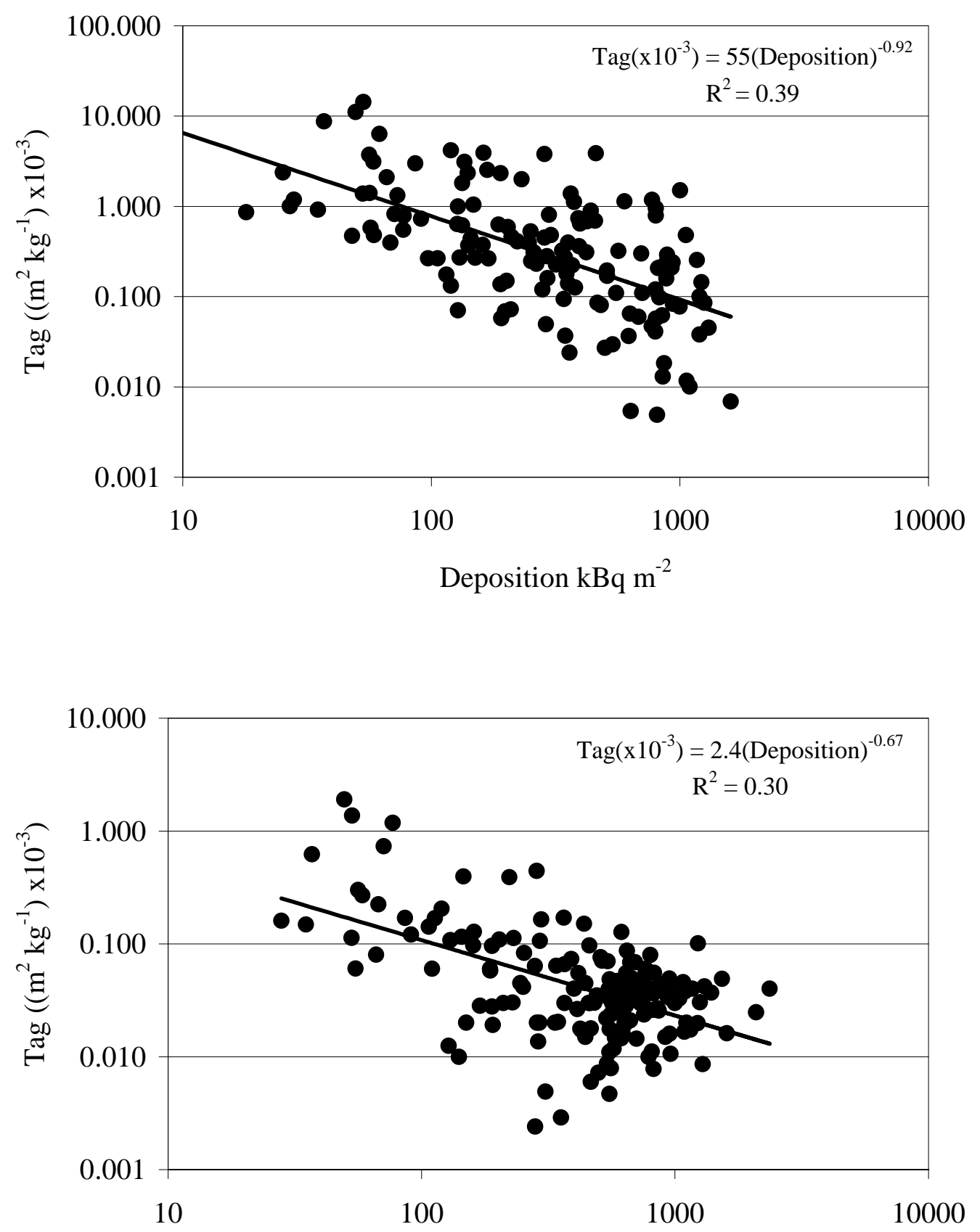

Deposition $\mathrm{kBq} \mathrm{m}{ }^{-2}$

Figure 1. Apparent relationship between the ${ }^{137} \mathrm{Cs}$ activity concentration in milk (fresh weight) [top] and potatoes (dry weight) [bottom] and measured deposition in soil. Note deposition is shown as $\mathrm{kBq} \mathrm{m}^{-2}$ and Tag is consequently quoted as $\times 10^{-3}$. See section 3 below for description of data sources. 


\section{LITERATURE REVIEW}

\subsection{Former Soviet Union}

A database $(n=197)$ of ${ }^{137}$ Cs activity concentrations in the milk of privately owned cows measured in Belarus in 1989 was analysed by Knatko et al. [8]. The authors reported a relationship between the ${ }^{137}$ Cs activity concentration in milk and deposition, with decreasing transfer at higher deposition:

$$
\text { Tag }=11 \times\left[{ }^{137} \mathrm{Cs} \text { in soil }\left(\mathrm{kBq} \mathrm{m}^{-2}\right)\right]^{-0.44}
$$

The authors suggested that the mechanism for their observation was saturation of ${ }^{137}$ Cs uptake by plants. They concluded that: (i) it was unlikely that variation in soil contributed to this observation (circa $90 \%$ of observations were classified as coming from the same soil type); and (ii) any effect of countermeasures would be too random to produce the relationship. The same group later reported a similar phenomenon for the transfer of ${ }^{137} \mathrm{Cs}$ to potatoes with increasing deposition suggesting that foodchain models should be adapted to incorporate non-linear transfer [15].

Konshin [9] presents a statistical evaluation of ${ }^{137} \mathrm{Cs}$ activity concentrations in grass in Belarus reporting a dependence of soil-to-grass transfer on soil ${ }^{137} \mathrm{Cs}$ activity concentrations. The author states that the results imply ${ }^{137} \mathrm{Cs}$ uptake by grass is more efficient at low soil concentrations and suggests saturation of soil to plant transfer.

An inverse relationship between average human whole body ${ }^{137} \mathrm{Cs}$ in a number of settlements and deposition has also been reported [10]. These authors noted a possible effect of countermeasure application but suggested this as unlikely. The authors concluded that spatial variation in soil sorption characteristics was the casual mechanism.

\subsection{Western Europe}

Two papers report decreasing ${ }^{137} \mathrm{Cs}$ transfer to vegetation with increasing soil contamination in Austria [12,13]. The first of these [12] reported the following relationships for the concentration ratio (CR) of the ${ }^{137} \mathrm{Cs}$ activity concentration in wheat crops to the activity concentration in soil for wheat straw and grain:

$$
\begin{aligned}
& \text { Grain CR } \left.=0.31 \times\left[{ }^{137} \mathrm{Cs} \text { in soil }(\mathrm{Bq} \mathrm{kg})^{-1}\right)\right]^{-0.61} \\
& \text { Straw CR }=0.07 \times\left[{ }^{137} \mathrm{Cs} \text { in soil }\left(\mathrm{Bq} \mathrm{kg}{ }^{-1}\right)\right]^{-0.55}
\end{aligned}
$$

However, CR values were also correlated with soil percentage clay. The second reference [13], which considered a range of crops, stated that the ${ }^{137} \mathrm{Cs}$ activity concentration in soil is the most important determinant of transfer to crops. Resuspension is suggested as a contributing factor, with the suggestion that the importance of Cs resuspension increases with decreasing deposition.

Phytoremediation trials on contaminated land at the Bradwell nuclear power station (UK) infer non-linearity in transfer of ${ }^{137} \mathrm{Cs}$ from soil to plant biomass; soil-plant concentration ratios decreased with increasing soil ${ }^{137} \mathrm{Cs}$ activity concentrations [11]. The authors suggest that their results indicate that the efficiency of phytoextraction will increase with successive harvests as soil ${ }^{137} \mathrm{Cs}$ reduces.

The concentration ratio of ${ }^{137} \mathrm{Cs}$ from organic soils to Calluna vulgaris, Juncus squarrosus and Vaccinium spp. in Ireland and Sweden was reported to reduce with increasing soil concentration [14]. A lack of correlation between vegetation and soil ${ }^{137} \mathrm{Cs}$ activity concentrations in vegetation and soil of German and Italian alpine pastures has also been reported [16].

\section{COMPILATION AND ANALYSES OF MILK AND POTATO DATA FROM THE fSU}

Data for the ${ }^{137} \mathrm{Cs}$ activity concentration in milk and corresponding soil samples in the fSU were obtained from reports of international programmes [17-21] and national monitoring programmes provided by collaborators as part of an assessment of radiocaesium fluxes and ingestion doses 
[see 22,23]. A total of 142 Tag values were available for milk and 165 for potatoes for a wide geographical area of Russia, Ukraine and Belarus to a distance of circa $500 \mathrm{~km}$ from the Chernobyl plant. Some of the data entries were settlement means whilst others were individual values. Only data collected between 1991-93 were included in the database; the data showed no significant change in ${ }^{137} \mathrm{Cs}$ transfer to either milk or potatoes over this time period. The database included values from the Ukrainian Chernobyl exclusion zone and Belarusian villages, which were subsequently evacuated. As already noted, ${ }^{137} \mathrm{Cs}$ transfer to both of these foodstuffs appeared to decline with increasing soil contamination (Figure 1) with no relationship between the activity concentration in milk or potatoes and soil contamination $\left(\mathrm{R}^{2}<0.1\right)$. The apparent relationships shown in Figure 1 being the result of a numerator, which does not change compared to a denominator, which increases by 3 orders of magnitude.

Transfer did not appear to be related to distance from the Chernobyl nuclear power plant $\left(\mathrm{R}^{2}<0.01\right)$. Los et al. [24] have previously reported an increase in Cs transfer with distance from the Chernobyl plant thought to be due to differences in the nature of fallout and a gradual change in soil type with distance. However, when samples were categorised according to soil type [25] significant differences were apparent; soils with the highest percentage clay having the lowest transfer.

Data originating from within the Ukrainian Chernobyl exclusion zone showed the ${ }^{137}$ Cs highest transfer to milk and potatoes. Data from settlements in Belarus subsequently evacuated exhibited the lowest transfer.

Whilst overall the data show the patters presented in Figure 1, sub-sets of the database do demonstrate a linear increase in the ${ }^{137} \mathrm{Cs}$ activity concentration in milk/potatoes with increasing soil contamination (e.g. milk from the Stolin district of Belarus).

\section{DISCUSSION}

A number of the papers reviewed above have suggested (or inferred) that radiocaesium root uptake is saturated. This would appear to be highly unlikely as whilst saturation of root uptake of radiocaesium has been observed above $1.37 \mathrm{mg} \mathrm{Cs}^{+} \mathrm{L}^{-1}$ in growth solutions [26], concentrations of $\mathrm{Cs}^{+}$in soil solutions are typically $<10 \mu \mathrm{g} \mathrm{L}^{-1}$ [27]. Furthermore, $1 \mathrm{MBq} \mathrm{m}^{-2}$ of ${ }^{137} \mathrm{Cs}$ will add only $0.3 \mathrm{mg} \mathrm{Cs}^{+} \mathrm{m}^{-2}$ compared to typical concentrations of stable Cs in soils in the FSU of $21-31 \mathrm{~g} \mathrm{~m}^{-2}$ [28]. The total concentration of alkali metals (notably $\mathrm{K}^{+}$) will also far exceed that of stable Cs. Our conclusion is in agreement with the findings of Nisbet \& Woodman [7] who found that, whilst highly variable, the transfer of radiocaesium from soil to crops was independent of soil radiocaesium concentrations over a range of 5-orders of magnitude in soil concentration.

Considering the data presented within Figure 1, we perhaps need to consider the purpose of its collection, which was to assess the intake of radiocaesium by populations in areas affected by the Chernobyl accident. Possibly some of the apparent pattern results from sampling strategies; for instance, is it unlikely that much sampling would be targeted at areas with low deposition and low transfer? Similarly it is unlikely that production of foodstuff continued in areas of especially high deposition and transfer.

Other authors have dismissed the potential contribution of countermeasure implementation [8]. However, as countermeasures were applied more intensively in areas of higher deposition they could contribute to the apparent lower ${ }^{137}$ Cs transfer to foodstuffs with increasing soil contamination. This suggestion is supported by our observation that within the Chernobyl exclusion zone, where countermeasure application was unlikely, ${ }^{137} \mathrm{Cs}$ was higher to potatoes and milk than areas of Belarus from which the population was subsequently removed and where countermeasures had been applied [22].

In general the distribution of radiocaesium deposition and transfer estimates from soil to vegetation within radioecological studies are log-normally distributed. Is it therefore less likely that sampling sites with both high deposition and high transfer will occur? Random sampling of ${ }^{137} \mathrm{Cs}$ deposition and plant to soil transfer values from databases of the transfer of radiocaesium from soil to vegetation in Cumbria (UK) [29] generates few high transfer-high deposition pairs (although we cannot replicate the patterns demonstrated in Figure 1 by such techniques). 


\section{CONCLUSION}

A number of datasets demonstrate either a lack of relationship between the ${ }^{137}$ Cs activity in crops/milk with soil contamination or a reduction in ${ }^{137} \mathrm{Cs}$ transfer with increasing soil contamination. This conflicts with the prerequisite that foodchain models are based upon, namely a positive linear relationship between soil and vegetation/animals, and conflicts with other findings [e.g. 7].

We feel that one previously suggested mechanism for this saturation of soil-plant transfer is unsubstantiated. A number of factors may contribute to the observation including sampling bias and the statistical distribution of data. In data from areas of the fSU affected by the Chernobyl accident there is also a potential impact of countermeasures. The wide range of ecological conditions encompassed by data collected in an unstratified manner over large spatial areas may also contribute to a lack of observed relationship between soil and plant/animal activity concentrations.

Whilst we have argued against previously suggested mechanisms for observations such as that demonstrated in Figure 1, and suggested other causal factors, we have not been able to provide a conclusive reason for such observations. Given the important implications for foodchain modelling further consideration of available data is required to more comprehensively answer this question.

\section{Acknowledgements}

This paper is based upon work started under the EC $4^{\text {th }}$ Framework projects RESTORE (F14-CT95-0021) and RECLAIM (ERBIC15-CT96-0209). We would like to thank colleagues involved in these projects for their useful discussions, most especially Natasha Semiochkina (GSF, Germany), Andrey Arkhipov (IRL, Ukraine), V. Drozdovitch (IPEP, Belarus) and N. Goncharova (Inst. Radiobiology, Belarus) for help in sourcing data.

\section{References}

[1] IAEA, Handbook of transfer parameter values for the prediction of radionuclide transfer in temperate environments, IAEA TECDOC 364, (IAEA, Vienna, 1994).

[2] H. Müller, G. Pröhl, Hlth. Phys., 64, 232 (1993).

[3] J. Brown, J.R. Simmonds, Farmland: a dynamic model for the transfer of radionuclides through terrestrial foodchains, NRPB-R275, (National Radiological Protection Board, Chilton, 1995).

[4] N.A. Beresford, R.W. Mayes, H.S. Hansen, N.M.J. Crout, K. Hove, B.J. Howard, Rad. Env. Biophys., 7, 2, 129 (1998).

[5] S.C. Sheppard, W.G. Evenden, J. Environ. Radioact., 8, 255 (1988).

[6] A.G. Gillett, N.M.J. Crout, S.M. Absalom, S.M. Wright, S.D. Young, B.J. Howard, C.L. Barnett, S.P. McGrath, N.A. Beresford, G. Voigt, Rad. Environ. Biophys., 40, 227 (2001).

[7] A.F. Nisbet, R.F. M. Woodman, Hlth. Phys., 78, 3, 279 (2000).

[8] V.A. Knatko, V.V. Gurkov, V.D. Asimova, E.B. Shpakovskaya, E.A. Shimanovich, J. Environ. Radioact., 22, 269 (1994).

[9] O.V. Konshin, Hlth. Phys., 63, 3, 307 (1992).

[10] H. Yasuda, S. Uchida, in IAEA-SM-339/1, (IAEA, Vienna, 1995), p. 259.

[11] N.R. Watt, N.J. Willey, S.C. Hall, A. Cobb, Acta Biotechnol., 22, 183 (2002).

[12] O. Horak, K. Muck, M.N. Gerzabek, in Proceedings of the International Symposium on Environmental contamination following a major nuclear accident, IAEA-SM-306/4, (IAEA, Vienna, 1990), p.29.

[13] M.H. Gerzabek, O. Horak, K. Mück, in Transfer of Radionuclides in Natural and Semi-Natural Environments, edited by G. Desmet P. Nassimbeni, M. Belli, (Elsevier Science Publishers Ltd., Essex, 1990), p. 611. 
[14] E.J. McGee, K.J. Johanson, M.J. Keatinge, H.J. Synnott, P.A. Colgan, Hlth. Phys. 70, 2, 215 (1996). [15] V.A. Knatko, V.U. Ageets, I.V. Shmigelskaya, I.I. Ivashkevich, J. Environ. Radioact, 48, 171 (2000).

[16] K. Bunzl, B.P. Albers, W. Schimmack, M. Belli, L. Ciuffo, S. Menegon, J. Environ. Radioact., 48, 145 (2000).

[17] G. Frank, P. Jacob, G. Pröhl, J.L. Smith-Briggs, F.J. Sandals, P.L. Holden, S.K. Firsakova, Y.M. Zhuchenko, A. Jouve, F.A. Tikhomirov, S.V. Mamikhin, T.V. Rusina, R.M. Alexakhin, S.V. Fesenko, N.I. Sanzharova, E. Nicaise, M. Medzadourian, I.A. Likhtarev, L. Kovgan, M.M. Kaletnyk, Optimal management routes for the restoration of territories contaminated during and after the Chernobyl accident, EUR 17627 EN, (European Commission, Brussels, 1998).

[18] K. Heinemann, Meßprogramm der Bundesrepublik Deutschland., Ergebnisse der Umweltmessungen in Rußland in der Zeit vom 21. Mai bis 11. Juni 1991, (Berichte Forschungszentrums, Jülich, 1991).

[19] K. Heinemann, R. Hille, Meßprogramm der Bundesrepublik Deutschland., Ergebnisse der Umweltmessungen in Rußland, Weirußland und der Ukraine in der Zeit vom 12. Mai bis 26. September 1992, (Berichte Forschungszentrums, Jülich, 1993).

[20] K. Heinemann, R. Hille, Meßprogramm der Bundesrepublik Deutschland., Ergebnisse der Umweltmessungen in Rußland, Weirußland und der Ukraine in der Zeit vom 17. Mai bis 2. September und vom 8. Oktober bis 1. November 1993, (Berichte Forschungszentrums, Jülich, 1994).

[21] P. Hill, R. Hille, Meßprogramm der Bundesrepublik Deutschland., Ergebnisse der Gazkörpermessungen in Rußland in der Zeit vom 17. Juni bis 4. Oktober 1991, (Berichte Forschungszentrums, Jülich, 1992).

[22] N.A. Beresford, S.M. Wright (editors), Self-help countermeasure strategies for populations living within contaminated areas of the former Soviet Union and an assessment of land currently removed from agricultural usage, FIGE-CT-2000-00102 and ERBIC15-CT96-0209, (ITE, Grange-over-Sands, 1999).

[23] H. Mehli, P. Strand (editors), Fluxes of ${ }^{137} \mathrm{Cs}$ in Chernobyl affected areas in Russia and Ukraine, FIGE-CT-2000-00102, (NRPA, Østerås, 1999).

[24] I.P. Los, I.A. Likhtarev, N.K. Shandala, V.S. Repin, O.A. Bobyleva, I. Yu. Komarikov, A. Yu. Vasil'ev, G.M. Gil'ko, G.M. Kajro, I.A. Kovgan, V.N. Stepanenko, V.V. Andreeva, in Environmental contamination following a major nuclear accident, IAEA-SM-306/143P, vol. 2, (IAEA, Vienna, 1990), p. 96.

[25] Food and Agriculture Organisation, Digital soil map of the world and derived soil properties, Version 3.5 (CD-ROM), (FAO, Rome, 1995).

[26] G. Shaw, R. Hewamanna, J. Lillywhite, J.N.B. Bell, J. Environ. Radioact., 16, 167 (1992).

[27] S. Young, University of Nottingham, pers comm.

[28] D.H. Oughton, B. Salbu, G. Riise, H. Lien, G. Østerby, A. Nøren, Analyst, 117, 481 (1992).

[29] N.A. Beresford, Radiocaesium variability in upland sheep flocks, Ph.D Thesis, (University of Nottingham, 2002). 